not only for leukaemia but for several other cancers, including cancer of the brain and nervous system, skin, and prostate and lymphomas. (Three regional American studies of mortality among veterinary surgeons from California, ${ }^{3}$ Missouri, ${ }^{4}$ and Illinois ${ }^{5}$ were too small for detailed analysis of different cancers.) The reason for the difference in findings between the American and British studies is not clear. It may be relevant, however, that the American study did not ascertain all deaths in a defined population, as this study did, but consisted of a proportionate analysis of deaths noted in the obituary columns of the fournal of the American l'eterinary Medical Association. As the authors pointed out, the proportionate mortality from certain causes can be inflated if other diseases have a reduced mortality, a frequent observation among professional groups. Another possible bias is differential reporting of deaths from cancer to the American Veterinary Medical Association compared with deaths from other causes.

Mortality from respiratory diseases among British veterinary surgeons is low, whether compared with the national mortality (ratio of observed to expected deaths 0.46 ) or with the mortality in social class I (ratio 0.75). Mortality from lung cancer was slightly higher than that in social class $I$, and although this was not statistically significant, it does not encourage the view that the deficiency of deaths from respiratory diseases is attributable simply to not smoking. Many veterinary surgeons live in rural districts with no atmospheric pollution, and this may play a part.

Cook and Dowling suggested that dogs may play a part in the aetiology of multiple sclerosis. ${ }^{6}$ In view of the greater than average contact by veterinary surgeons with dogs it is relevant that no excess mortality from multiple sclerosis was observed in this study (two observed deaths, 1.9 expected), a finding that is in keeping with more recent work. ${ }^{7}$ An increased risk of zoonotic infections and of injuries while handling animals is well known ${ }^{8}$ but was not reflected in the underlying causes of death in this study, although brucellosis was mentioned incidentally on two death certificates and two deaths were due to riding accidents. No support was found for the hypothesis that veterinary surgeons may be at increased risk of death from cancer because of exposure to oncogenic viruses in the course of their work.

I am grateful for help in this study to Andrew Scott, Jo Moffat, Mary Hall, Carol Hermon, and Angela Balkwill; to Mr R Marshall and other staff of the Royal College of Veterinary Surgeons; to the Office of Population Censuses and Surveys; and to the Cancer Research Campaign for its financial support.

\section{References}

${ }^{1}$ Registrar General. Occupational mortality. Decennial supplement. England and Wales 1961. London: HMSO, 1971.

2 Blair A, Hayes HM Jr. Mortality patterns among US veterinarians, 1947-1977: an expanded study. Int $\mathcal{F}$ Epidemiol $1982 ; 4: 391-7$.

${ }^{3}$ Fasal E, Jackson EW, Klauber MR. Mortality in California veterinarians. f Chron Dis 1966;19:293-306.

4 Botts RP, Edlavitch S, Payne G. Mortality of Missouri veterinarians. Fournal of the American Veterinary Medical Association 1966;149: 499-504.

5 Schnurrenberger PR, Martin RJ, Walker JF. Mortality in Illinois reterinarians. Fournal of the American Veterinary Medical Association 1977; 170:1071-5.

- Cook SD, Dowling PC. A possible association between house pets and multiple sclerosis. Lancet 1977 ;i :980-2.

${ }^{7}$ Read D, Nassim D, Smith P, Patterson C, Worlow C. Multiple sclerosis and dog ownership: a case control investigation. F Neurol Sci 1982;55: 359-67.

${ }^{8}$ Constable PJ, Harrington JM. Risks of zoonoses in a veterinary service. Br Med $\mathcal{F} 1982 ; 284: 246-8$.

(Accepted 14 fuly 1983)

\title{
Precancerous lesions of the cervix uteri in infertile women
}

\author{
N HOLST, T ÅBYHOLM
}

\begin{abstract}
A study of 318 patients with tubal infertility and a control group of 200 unselected infertile women yielded 14 $(4.4 \%)$ and $1(0.5 \%)$, respectively, with precancerous lesions of the cervix uteri. The one patient in the control group with severe dysplasia was later shown to have tubal infertility. The overall incidence of premalignant lesions of the cervix uteri as reported to the National Cancer Registry of Norway was $0.1 \%$ for the age group and period studied.

Women with tubal infertility represent a small but comparatively high risk group for the development of precancerous lesions of the cervix uteri.
\end{abstract}

\footnotetext{
Department of Obstetrics and Gynaecology, National Hospital of Norway, University of Oslo, Rikshospitalet, Oslo, Norway N HOLST, MD, senior registrar

T ÅBYHOLM, MD, PHD, assistant professor

Correspondence to: Dr N Holst.
}

\section{Introduction}

In Norway cervical neoplasia is the most common cancer of the female reproductive tract. Each year about 400 new cases of invasive cervical cancer and 800 to 900 cases of severe dysplasia and carcinoma in situ of the cervix uteri are reported to the National Cancer Registry. ${ }^{1}$ Some $70 \%$ of these are in women aged 20-39 years. Cervical neoplasia is of special interest because it may be detected early by cytological screening. Hence defining populations at high risk of developing cervical cancer would help in reducing the incidence of the disease.

Several aetiological factors have been postulated in cervical carcinogenesis. There is much evidence suggesting that a sexually transmitted virus-for example, herpes simplex virus-may be implicated. ${ }^{2-4}$ The virus of condyloma accuminatum is also reportedly associated with cervical neoplasia. ${ }^{5}$ Other sexually transmitted diseases that have been postulated as a factor include syphilis, gonorrhoea, and trichomoniasis and genital infections with mycoplasma, chlamydia, and cytomegalovirus. ${ }^{3-8}$ Also associated with an increased risk of the disease are early age at first intercourse and early age at first marriage, multiple sexual partners and multiple marriages, great coital frequency, multiparity, and low social class. ${ }^{36}{ }^{9}$ A circumcised male partner is reportedly associated with a low risk of cervical cancer. ${ }^{3}$ s An increased risk from oral contraceptives has not been proved. ${ }^{10}$

In women with tubal infertility many of these risk factors 
may be present. Tubal infertility is usually a result of pelvic inflammatory disease and hence is associated with agents that may predispose to cervical neoplasia. These women may therefore represent a population at high risk of developing the disease.

We report a study aimed at ascertaining the incidence of premalignant and malignant lesions of the cervix uteri in women with tubal infertility. As controls we studied an unselected group of infertile women.

\section{Patients and methods}

The study group comprised 318 patients who between 1975 and 1979 underwent laparotomy in the infertility clinic of our department because of tubal infertility. Patients with endometriosis were excluded. Before operation all couples underwent a complete routine investigation for their infertility. This included cytological smears from the cervix and diagnostic curettage. When dysplastic or precancerous changes were suspected colposcopy and biopsy were performed. In patients without obvious disease cytological follow up was performed by us in only one third of cases, the remainder being referred back to their own physician or gynaecologist.

The records of all 318 patients with tubal infertility were studied and the incidence of histologically verified dysplastic changes and carcinoma in situ noted. As controls we studied an unselected group of 200 infertile women who in 1980 underwent diagnostic curettage as part of the routine evaluation of infertility. The records of these patients were also studied and the incidence of dysplasia and carcinoma in situ diagnosed by cervical biopsy noted. There was no difference between the study group and controls in age, duration of infertility, and parity.

\section{Results}

The table shows the numbers of patients in the two groups with dysplastic changes and carcinoma in situ of the cervix uteri. No case of invasive cancer was diagnosed. A total of 31 patients in the study

Patients with dysplasia and carcinoma in situ of cervix uteri

\begin{tabular}{|c|c|c|c|c|}
\hline & \multicolumn{2}{|c|}{$\begin{array}{l}\text { Study group of women } \\
\text { with tubal infertility } \\
\qquad(n=318)\end{array}$} & \multicolumn{2}{|c|}{$\begin{array}{l}\text { Unselected control group } \\
\text { of infertile women } \\
(n=200)\end{array}$} \\
\hline & No & $\%$ & No & $\%$ \\
\hline $\begin{array}{l}\text { Slight dysplasia } \\
\text { Moderate dysplasia } \\
\text { Severe dysplasia } \\
\text { Carcinoma in situ }\end{array}$ & $\begin{array}{r}7 \\
10 \\
8 \\
6\end{array}$ & $\begin{array}{l}2 \cdot 2 \\
3 \cdot 1 \\
2 \cdot 5 \\
1 \cdot 9\end{array}$ & $\begin{array}{l}0 \\
1 \\
1 \\
0\end{array}$ & $\begin{array}{l}0.5 \\
0.5\end{array}$ \\
\hline Total & 31 & $9 \cdot 7$ & 2 & 1.0 \\
\hline
\end{tabular}

group (9.7\%) had dysplasia (slight, moderate, or severe) or carcinoma in situ. True precancerous lesions (severe dysplasia and carcinoma in situ) were diagnosed in $14(4.4 \%)$. In all of these patients a conisation was performed. In the 17 patients $(5.3 \%)$ with slight and moderate dysplasia cryosurgery was performed. Later cytological smears were normal in all 31 patients.

Of the control group of 200 unselected infertile women, two were found to have dysplasia of the cervix uteri. In one patient this was moderate and in the other severe. No case of carcinoma in situ or of invasive cancer of the cervix uteri was diagnosed. Further evaluation of infertility in the two patients with dysplasia showed tubal infertility in both. A total of 41 patients in the control group were found to have tubal infertility (20.5\%).

\section{Discussion}

All of our patients in the study and control groups were between 20 and 39 years old. During 1975 to 1979 a total of 3058 cases of severe dysplasia and carcinoma in situ in women aged 20-39 were reported to the National Cancer Registry of
Norway. ${ }^{1}$ This represents an incidence of 112 cases per 100000 women of that age, or $0.1 \%$. In our study group the incidence of severe dysplasia and carcinoma in situ was $4.4 \%$. Although the study group was relatively small (318 patients), the results suggest that women with tubal infertility have a definitely increased risk of developing premalignant lesions of the cervix uteri. The cause of the precancerous lesions in these patients is likely to be pelvic inflammatory disease, which is known to be associated with cervical neoplasia. ${ }^{36-8}$

Among 200 unselected infertile controls, one patient had a cervical precancerous lesion (severe dysplasia) and one moderate dysplasia. Both patients were found to have tubal infertility, which suggests that infertile women who do not have tuba disease do not have an increased risk of premalignant changes.

Most of our patients were from urban districts in eastern Norway. In reports to the National Cancer Registry the region had a somewhat higher incidence of cervical malignancy than the rest of Norway. This, however, does not explain the highly increased rate of premalignant lesions in patients with tubal infertility.

Each year in Norway some 3000 new couples seek help for infertility, and in about a quarter of these the cause is tubal. ${ }^{11}$ Given our results, we should expect a diagnosis of severe dysplasia or carcinoma in situ to be made in $4-5 \%$ of these patients-that is, in about 35 new patients each year. Hence roughly $6 \%$ of cases of precancerous lesions of the cervix uteri in women aged 20-39 years reported each year to the National Cancer Registry will be associated with tubal infertility. This emphasises that women with tubal infertility represent a small but high risk group for the development of premalignant lesions of the cervix uteri.

It is of great importance to be aware of these high risk patients and include precautionary measures-cytological smears and colposcopy - as part of the diagnostic procedure. In our study no case of invasive cancer occurred. Rigorous follow up of the patients, however, might disclose such cases and cases of later developing precancerous lesions.

\section{References}

1 National Cancer Registry of Norway (Oslo). Annual Reports 1975-9.

2 Anonymous. Cervical intraepithelial neoplasia. Lancet 1982 ;ii:365-7.

${ }^{3} \mathrm{Kessler}$ II. Etiological concepts in cervical carcinogenesis. Gynecol Oncol $1981 ; 12: S 7-S 24$.

${ }^{4}$ Kessler II. On the etiology and prevention of cervical cancer-a status report. Obstet Gynecol Surv 1979;34:790-4.

${ }^{5}$ Meisels A, Roy M, Fortier M, et al. Human papillomavirus infection of the cervix. The atypical condyloma. Acta Cytol 1981;25:7-22.

${ }^{6}$ Hulka BS. Risk factors for cervical cancer. $\mathcal{F}$ Chronic Dis 1982;35:3-11.

${ }^{7}$ Alexander ER. Possible etiologies of cancer of the cervix other than herpesvirus. Cancer Res 1973;33:1485-96.

${ }^{8}$ Furgyik S, Astedt B. Gonorrheal infection followed by an increased frequency of cervical carcinoma. Acta Obstet Gynecol Scand 1980;59 521-4.

${ }^{9}$ Lambert B, Morisset R, Bielmann P. An etiologic survey of clinical factors in cervical intraepithelial neoplasia. A transverse retrospective study. F Reprod Med 1980;24:26-31.

${ }^{10}$ Swan SH, Brown WL. Oral contraceptive use, sexual activity, and cervical carcinoma. Am $\mathcal{Y}$ Obstet Gynecol 1981 ;139:52-7.

"Sørensen SS. Infertility factors. Their relative importance and share in an unselected material of infertility patients. Acta Obstet Gynecol Scand 1980;59:513-20.

(Accepted 26 fuly 1983)

\section{Correction}

Epileptic seizures in a population of 6000-I: Demography, diagnosis, and classification, and role of the hospital services

Two errors occurred in this article by Drs D M G Goodridge and S D Shorvon (3 September, p 641). The lifetime prevalence of epilepsy, excluding single seizures, in this population was $16 \cdot 7$ per 1000 and not 17 per 1000 as stated, and in table $I$ the present study prevalence rate should have read $20 \cdot 3$, not $20 \cdot 5$. 